\title{
Endovascular treatment of a tentorial dural arteriovenous fistula
}

\author{
Omar Choudhri, M.D. and Michael P. Marks, M.D. \\ Department of Neurosurgery \& Interventional Neuroradiology, Stanford University Medical Centre, Stanford, \\ California
}

Tentorial dural arteriovenous fistulae are rare intracranial fistulae, in which the fistula pocket is present within the leaves of tentorium cerebelli. These tentorial fistulae can be rarely present near the galenic complex, where they can engorge the deep venous system and cause symptoms of venous hypertension. We present an interesting case of endovascular treatment of a galenic tentorial dural arteriovenous fistula in a patient with headaches and imbalance. The fistula was accessed through the artery of Davidoff and Schecter from the posterior cerebral artery supplying the fistula. The fistula was completely embolized using Onyx and with preservation of vein of Galen.

The video can be found here: http://youtu.be/igX2X5tfvrg.

(http://thejns.org/doi/abs/10.3171/2014.V2.FOCUS14184)

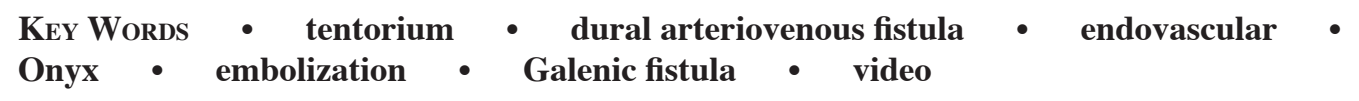

Manuscript submitted May 2, 2014.

Accepted June 10, 2014.

Please include this information when citing this paper: DOI: 10.3171/2014.V2.FOCUS14184.

Address correspondence to: Omar Choudhri, M.D., Department of Neurosurgery, Stanford University School of Medicine, 300 Pasteur Drive MC5327, Stanford, California. email: ochoudhri@stanford. edu. 